\title{
Combined Toxicity and Toxicity Persistence of Antidepressants Citalopram and Mirtazapine to Zooplankton Daphnia Magna
}

\author{
Yunfeng Ma \\ China Pharmaceutical University \\ Dong Xu \\ Nanjing University \\ Chenyang Li \\ China Pharmaceutical University \\ Shu Wei \\ China Pharmaceutical University \\ Ruixin Guo \\ China Pharmaceutical University \\ Yang Li \\ Wuhan University Zhongnan Hospital \\ Jianqiu Chen ( $\nabla$ cjqer@cpu.edu.cn ) \\ China Pharmaceutical University \\ Yanhua Liu \\ China Pharmaceutical University
}

\section{Research Article}

Keywords: Antidepressants, Zooplankton, Abnormal behavior, Joint toxicity, Exposure and recovery, Aquatic risk.

Posted Date: October 13th, 2021

DOI: https://doi.org/10.21203/rs.3.rs-608054/v2

License: (1) (i) This work is licensed under a Creative Commons Attribution 4.0 International License. Read Full License 


\section{Abstract}

Citalopram (CTP) and mirtazapine (MTP) are two typical psychoactive drugs used for the depression treatment. As emerging pollutants, CTP and MTP has been given widely concern because they are active substances for organisms. Therefore, the ecotoxicological risks of aquatic organisms should be paid more attention to. In this study, the effects of CTP and MTP on the feeding behavior, heartbeat, nutritional enzymes and related gene transcriptions of Daphnia magna were investigated under single and mixed environmental stress. Meanwhile, the recovery of exposed $D$. magna was studied to analyze the toxic persistence of those pollutants. After 24 -hexposure, the ingestion rate decreased by $34.2 \%$ and $21.5 \%$, in the group of $\mathrm{C}-\mathrm{H}$ and Mix-H respectively. After 24-h recovery, the feeding behavior of $D$. magna was stimulated by compensatory stimulation. In exposure period, the heartbeat rate of $D$. magna increased by $132.3 \%, 69 \%, 111.9 \%, 139.4 \%$, and $92.4 \%$, in the group of $\mathrm{C}-\mathrm{L}$, $\mathrm{C}-\mathrm{H}$, $M-L, M-H$ and Mix-L respectively, and was recovered during the recovery period. The activity of a-amylase (AMS) and trypsin were significantly changed in most of the exposed daphnia, both in the exposure period and recovery period. CTP/MTP exposure stimulated transcription of the aamylase gene. $\mathrm{M}-\mathrm{H}$ and Mix-H exposure inhibited transcription of the trypsin gene and other stimulated transcriptions. After 24-h recovery, the stimulative or inhibitory effects were alleviated. There were different responses between gene transcription and enzyme activity. In conclusion, our results highlighted the toxic effects of single and mixed pollution of CTP and MTP on feeding, heartbeat, enzymes and genes of $D$. magna.

\section{Highlights:}

1. The feeding behavior of $D$. magna was inhibited by citalopram (CTP).

2. A form of overcompensation of the feeding behavior occurred after recovery.

3. The heartbeats of $D$. magna increased after exposed to CTP and mirtazapine (MTP).

4. The exposure of CTP and MTP disturbed the digestive system in D. magna.

5. The gene expression of a-amylase and trypsin was changed after exposure.

\section{Introduction}

The use of antidepressants has been increasing considerably since 2000 , and they were inevitably released into the environments and caused serious environmental pollution (Sehonova et al., 2018). As emerging contaminants, CTP and MTP are not target pollutants in the waste water treatment plant (WWTP). The average CTP removal efficiency in WWTP was 25\% (Gros et al., 2020), therefore the effluent concentration of CTP was still considered high (Kuzmanovic et al., 2015; Petrie et al., 2015). CTP and MTP are typical antidepressant drugs, widely used for the depression treatment (Cipriani et al., 2018). Previous studies have found that more than $10 \%$ of psychoactive drugs were excreted into the aquatic environments in their active form (Balakrishna et al., 2017), and about 12\% of CTP and 6-20\% of MTP was excreted into the aquatic environments (Bergheim et al., 2012; Gundlach et al., 2021).

Recently, the use of CTP and MTP continues to increase, both drugs can be found in most environment compartments, such as sediments, surface water, groundwater, etc. (Silva et al., 2015; Proctor et al., 2021). Golovko et al. (2020) reported that the average concentrations of CTP and MTP in surface water of Lake Ekoln in Sweden were 0.59 and $1.1 \mathrm{ng} / \mathrm{L}$, respectively. The detection frequency of MTP at a university hospital in loannina located in northwestern Greece was $>73 \%$ and the average concentration was $8.3 \mathrm{ng} / \mathrm{L}$ (Kosma et al., 2019). CTP was detected in untreated sewage in Denmark, with its concentration range of 0.19-10.3 $\mathrm{gg} / \mathrm{L}$ (Styrishave et al., 2011). Antidepressants maybe highly dangerous for aquatic ecosystems (Minguez et al., 2016). The risks of disturbances in behavior and endocrine system may be expected in fish exposed to psychotropic drugs-contaminated environment (Giang et al., 2018). However, the potential impacts of CTP/MTP pollution on aquatic organisms were limited.

The aquatic environmental risks of CTP and MTP have received more attentions. For example, Bachour et al. (2020) observed a significant decrease in swimming activity of zebrafish exposed to CTP with a concentration of $373 \mu \mathrm{g} / \mathrm{L}$. The inhibition rate of Acetyl cholinesterase (ACHE) activity was 73\% of D. magna exposed to CTP with a concentration of $1 \mathrm{~g} / \mathrm{L}$ (Yang et al., 2017). Assessment of individual chemical is a common tool for ecological risk assessment of pollutants. However, many pollutants usually exist simultaneously in the aquatic environments. When aquatic organisms were exposed to a mixture of pollutants simultaneously, the toxicity of those pollutants to organisms may be superimposed or reduced. (Lari et al., 2017; Liu et al., 2018; Bachour et al., 2020; Hossain et al., 2021). It was revealed that the 1:1 binary mixture of CTP and tramadol may cause significant decrease in swimming activity of zebrafish during dark conditions when compared with individuals CTP and tramadol (Bachour et al., 2020). In the depression treatment, CTP and MTP were often used in combination (Zhuang and Hospital, 2019), and appeared together in the environment. Therefore, the combined toxicity of CTP and MTP was worthy of more attentions.

Because of the characteristics of easy cultivation, short life cycle and high sensitivity to pollutants, $D$. magna is a good model organism for the evaluation of aquatic environment pollution (He et al., 2019; Tkaczyk et al., 2021). D. magna has been used to assess the acute toxic effects of MTP or CTP (Yang et al., 2017), while many adverse effects are not well characterized. Toxicology studies have suggested that the feeding behavior and heartbeat of $D$. magna were used to assess the sub-lethal effects of pollutants. Assessment of effects on feeding activity is a 
valuable tool for determination of early effects induced by bioactive substances. The daphnid heart responded to sublethal levels of various environmental stressors. Heart may be considered as a promising sensor of effects induced by stressful factors in the aquatic environment and as a model for testing cardioactive drugs (Bownik, 2017, 2020). The pollutant concentration of in the environment is constantly changing. However, few studies have analyzed the recovery effects after exposed to CTP/MTP of D. magna. In previous studies, Yan et al. (2018) revealed that after 7-day exposed-recovery to sulfamethazine (SMZ), the activities of SOD and MDA of zebrafish were reversed. However, after 1-week exposed-recovery to rifampicin, bacterial communities of Gambusia affinis were not able to recover in terms of diversity or composition (Carlson et al., 2017). It is worth studying whether the aquatic organisms could fully recover when the pollutants were removed. Thus, the studies of the abnormal behavior of $D$. magna caused by CTP and MTP were performed to understand the aquatic ecological risks of these two substances.

Thus, to deepen the understanding of potential toxicity of CTP and MTP, the individual and combined toxicity on the feeding behavior, heart rate, nutritional enzymes, and related gene transcription of $D$. magna were thoroughly studied in this study during exposure and recovery periods. There were three research objectives in this study: 1) the effects of CTP and MTP on the feeding behavior and heartbeat of $D$. magna were studied under single and mixed environmental stress; 2 ) the recovery of $D$. magna after exposure was study to evaluate the toxicity persistence of CTP and MTP.; 3) the potential toxic mechanism of CTP and MTP was studied by monitoring the digestive enzymes and related genes of $D$. magna. The findings were feasible to evaluate the potential risks of CTP and MTP in aquatic ecosystems.

\section{Materials And Methods}

\subsection{Chemicals}

Citalopram (CTP; CAS: 59729-33-8) was purchased from Sichuan Kelun Pharmaceutical Co., Ltd (China), and Mirtazapine (MTP; CAS: 85650-528) was purchased from N.V. Organon (Netherlands). The physiochemical properties of the target compounds are listed in Table S1 (Supporting Information). The assay kits for measuring the digestive enzyme activity of a-Amylase (AMS) and trypsin were purchased from Nanjing Jiancheng Bioengineering Institute (China). Trizol reagent was purchased from New Cell \&Molecular Biotech Co., Ltd (Suzhou, China). Reverse transcriptase was purchased from Vazyme Biotech Co., Ltd (Nanjing, China). The concentrations of CTP and MTP in each group were detected by HPLC (SOD-M 20A, Shimadzu, Japan), equipped with DAD detector and Baseline C-18 column (4.6 mm $\times 150 \mathrm{~mm}, 5 \mu \mathrm{m})$. The mobile phase contains methanol and water with the ratio of 50:50, (V/V). The detection wavelength was $237 \mathrm{~nm}$ for CTP and $240 \mathrm{~nm}$ for MTP, the flow rate was $1.0 \mathrm{~mL} / \mathrm{min}$, the column temperature was $35^{\circ} \mathrm{C}$, and the injection volume was $20 \mu \mathrm{L}$. The retention time of CTP and MTP was 5.2 and 2.7 min, respectively.

\subsection{Culture program of Chlorella pyrenoidosa and D. magna}

Chlorella pyrenoidosa (C. pyrenoidosa) was obtained from Institute of aquatic biology, Chinese Academy of Sciences (Wuhan, China), cultured in the BG-11, and maintained at the temperature of $25.0 \pm 1.0^{\circ} \mathrm{C}$ with a light-dark cycle of $16: 8 \mathrm{~h}$. As an inorganic salt, BG-11 was the mineral salt medium provided to the microalgae and there was no external carbon source provided to the microalgae. Microalgae grew autotrophically under light conditions. Before the experiment began, C. pyrenoidosa were harvested by centrifuging at $4000 \mathrm{rpm}$ for $10 \mathrm{~min}$. D. magna was cultured in water with medium hardness and maintained at the temperature of $20.0 \pm 1.0^{\circ} \mathrm{C}$ with a light-dark cycle of $16: 8 \mathrm{~h}$. $C$. pyrenoidosa was used as the food source for $D$. magna.

\subsection{Feeding behavior experiment}

Feeding tests were conducted with 7-day-old D. magna under exposure and recovery for $24 \mathrm{~h}$. Acute toxicity tests are described in SI-S1. The $1 / 80 \mathrm{EC}_{50}$ and $1 / 20 \mathrm{EC}_{50}$ of CTP $(0.36$ and $1.45 \mathrm{mg} / \mathrm{L})$ and MTP $(0.25$ and $1.03 \mathrm{mg} / \mathrm{L})$ were used for the further single exposure experiment. The summary of the experimental process is listed in Table 1. Five replicates were set for each group, and five $D$. magna were employed in each replicate. The tests of feeding inhibition were conducted in $100 \mathrm{~mL}$ beakers, containing $60 \mathrm{~mL}$ of exposure solution. Microalgae was usually cultured to logarithmic growth stage were fed $\left(1 \times 10^{6} \mathrm{cells} / \mathrm{mL}\right)$ to $D$. magna after centrifugal cleaning. To avoid the growth of microalgae, all groups were conducted in the dark condition. The solution before and after 24-h exposure and 24-h recovery in each beaker were shaken fiercely to resuspended the $C$. pyrenoidosa cells. The algal density was detected by spectrophotometry at $680 \mathrm{~nm}$ for calculating the feeding rate (Li et al., 2020). One D. magna was taken from each beaker, and the heartbeat of $D$. magna was recorded by video under Nikon SMZ1000 stereomicroscope for 2 minutes. 
Table 1

Summary of the treatment process applied for single and mixture compound(s) feeding tests during exposure and restores period.

\begin{tabular}{|c|c|c|c|c|c|c|c|c|c|}
\hline \multirow[t]{2}{*}{ Group } & & \multicolumn{2}{|c|}{$\begin{array}{l}\text { Nominal concentration } \\
(\mathrm{g} / \mathrm{L})\end{array}$} & \multicolumn{2}{|c|}{$\begin{array}{l}\text { Actual concentration } \\
(\mathrm{mg} / \mathrm{L})\end{array}$} & \multirow[t]{2}{*}{$\begin{array}{l}\text { Starvation } \\
\text { treatment(h) }\end{array}$} & \multirow{2}{*}{$\begin{array}{l}\text { Exposure } \\
\text { time (h) }\end{array}$} & \multirow{2}{*}{$\begin{array}{l}\text { Starvation } \\
\text { treatment } \\
\text { (h) }\end{array}$} & \multirow[t]{2}{*}{$\begin{array}{l}\text { Restores } \\
\text { time(h) }\end{array}$} \\
\hline & & Citalopram & Mirtazapine & Citalopram & Mirtazapine & & & & \\
\hline Control & & 0 & 0 & 0 & 0 & 24 & 24 & 24 & 24 \\
\hline \multirow[t]{2}{*}{ Citalopram } & C-L & 0.36 & 0 & 0.34 & 0 & 24 & 24 & 24 & 24 \\
\hline & $\mathrm{C}-\mathrm{H}$ & 1.45 & 0 & 1.29 & 0 & 24 & 24 & 24 & 24 \\
\hline \multirow[t]{2}{*}{ Mirtazapine } & $M-L$ & 0 & 0.25 & 0 & 0.17 & 24 & 24 & 24 & 24 \\
\hline & $\mathrm{M}-\mathrm{H}$ & 0 & 1.03 & 0 & 1.02 & 24 & 24 & 24 & 24 \\
\hline \multirow{2}{*}{$\begin{array}{l}\text { Mix } \\
\text { (Citalopram } \\
\text { and } \\
\text { Mirtazapine) }\end{array}$} & $\begin{array}{l}\text { Mix- } \\
\mathrm{L}\end{array}$ & 0.18 & 0.125 & 0.18 & 0.08 & 24 & 24 & 24 & 24 \\
\hline & $\underset{H}{\mathrm{Mix}-}$ & 0.72 & 0.52 & 0.54 & 0.44 & 24 & 24 & 24 & 24 \\
\hline
\end{tabular}

\subsection{Measurements of enzyme response assay}

Under the same conditions as the feeding assays, 245 D. magna were cultured at the same time for each group. 200 of them were used for the enzyme response experiment and the rest was for gene transcription. In general, samples were collected after $24 \mathrm{~h}$ of exposure and $24 \mathrm{~h}$ of recovery for further enzyme gene analyze. After $24 \mathrm{~h}$ of exposure and $24 \mathrm{~h}$ of recovery, D. magna was collected and mixed with $0.9 \%$ sodium chloride solution in the ratio of $1: 9$ and then homogenize thoroughly on ice. Then the homogenates were centrifuged at 8000 rpm at $4{ }^{\circ} \mathrm{C}$ for 10 min, the supernatant was taken out to measure the total protein (TP) content and the activities of AMS and trypsin according to the instructions of respective assay kits. All the operations were carried out at a temperature of $4^{\circ} \mathrm{C}$. Steps of the measurement are provided in detail in the S1-3 (Supporting Information).

\subsection{Extraction of total RNA and reverse transcription}

D. magna were performed as experimental animals to detect gene transcription under different stress conditions, three replicates were set for each group. 15 D. magna were involved in each replicate for detecting the gene transcription of AMS and trypsin. After 24-h exposure and 24-h recovery, $D$. magna was removed from the culture medium and washed twice with double distilled water, and then transferred to a homogenizer containing Trizol reagent to extract total RNA (under the $4^{\circ} \mathrm{C}$ ). Nanodrop 2000 was performed to detect the concentration of total RNA (Thermo Fisher Scientific, USA). To obtain cDNA, $2 \mu \mathrm{g}$ of total RNA was used for reverse transcription with HiScript II Reverse Transcriptase (Vazyme, Nanjing, China) following the manufacturer instructions.

The gene transcription of $D$. magna exposed to CTP and MTP was analyzed by real-time quantitative polymerase chain reaction (qPCR). $\beta$-actin gene was used as the internal standard gene and the specific primers were designed for two target genes (trypsin and AMS). The primers for qPCR were designed in National Center for Biotechnology Information according to the known sequences. The primer specificity information is listed in Table S2 (Supporting Information). The transcriptions of these genes were conducted by SYBR Green PCR Master Mix (Vazyme, Nanjing, China) according to the instruction. Cycling parameters were set as follows: one cycle of $95^{\circ} \mathrm{C}$ for $30 \mathrm{~s}$, followed by 40 cycles of $95^{\circ} \mathrm{C}$ for $10 \mathrm{~s}$ and $60^{\circ} \mathrm{C}$ for $30 \mathrm{~s}$. Then, the formation of specific products was determined by melting curve analysis. The target gene transcription values were calculated by the 2 - $\triangle C T$ method (Livak and Schmittgen, 2001). Three independent biological repeats were performed in these experiments.

\subsection{Data analyze}

Statistical analyses were performed by SPSS statistics 26.0 software. The difference between the experimental group and the control group were performed by an ANOVA. The correlation between activity of digestive enzymes and their corresponding genes were analyzed by bivariate correlation analysis. The experimental data were present as mean \pm standard deviation. ${ }^{\star} p<0.05$ and ${ }^{*} p<0.01$ were set as the significance levels of all calculations. Data visualization was performed using Origin 8.0 software.

\section{Results And Discussion}

\subsection{Feeding inhibition of $D$. magna caused by psychoactive drugs}

The feeding inhibition experiments of $D$. magna were used to study the single or joint toxicity of CTP/MTP to aquatic organisms during exposure and recovery period, and the results are shown in Fig. 1A and 1B, respectively. After $24 \mathrm{~h}$ of exposure, the ingestion rate decreased by $34.2 \%$ and 
$21.5 \%$, in the group of $\mathrm{C}-\mathrm{H}$ and $\mathrm{Mix}-\mathrm{H}$ respectively. There was no significant decrease in feeding rate in the other exposure groups ( $p>0.05)$. Food consumption of $D$. magna decreased with increasing CTP concentration, which indicated a concentration-response relationship (Lari et al., 2017). Compared with the control, there were no obvious differences in feeding behavior when exposed to MTP for $24 \mathrm{~h}$, which showed that $D$. magna was more susceptible to CTP than MTP. In the binary mixture toxicity experiment, the feeding rate decreased significantly in the group of Mix- $\mathrm{H}$, but it was higher than the group of $\mathrm{C}-\mathrm{H}$. Considering the groups the concentrations of CPT Mix- $\mathrm{H}$ group, the results can be interpreted as follows. It remains to be further verified whether the two compounds in terms of additivity, synergistic or antagonistic. CTP can cause oxidative stress in D. magna. There were several studies that showed that a significant increase of ROS generation, accompanied by increased T-AOC and MDA of D. magna, was induced by CTP exposure (Yang et al., 2018). The activity of Superoxide dismutase (SOD) of $D$. magna significantly increased, while ACHE activity was inhibited (Yang et al., 2017). The neurons and muscle fibers of $D$. magna were induced to change by toxic oxygen free radicals, which induced swimming behavior disorder (Bownik et al., 2020). The D. magna needs the coordination of nervous system to complete food filtering and feeding behavior. The neuroactive substance (chlorpromazine) can cause the lack of coordination and inhibition of feeding behavior of $D$. magna (de Alkimin et al., 2020). The addition of SSRI might enhance the movement behavior of $D$. magna (Campos et al., 2012a). When exposed to high concentrations of CTP, the ingestion rate was significantly reduced. It may be related to the loss of coordination caused by the stimulation of neuroactive substances to the motion of the $D$. magna and oxidative damage.

After $24 \mathrm{~h}$ of recovery, the ingestion rate increased by $34.2 \%$ and $21.5 \%$, in the group of $\mathrm{M}-\mathrm{L}$ and $\mathrm{C}-\mathrm{H}$ respectively. This may be due to the mechanism of overcompensation (Lv et al., 2018; Liu et al., 2019). The feeding inhibition reversed into hormesis from the exposure period to the recovery period. The overcompensation is an exceeding compensation after the animals suffer damaging stress which helps to restore its nutritional status (Liu et al., 2018). Liu et al. (2019) found that $D$. magna enhanced its self-protection mechanism by eating more food to better adapt to the new environment when exposed to Bisphenol analogues (BPs).

\subsection{Heart rate}

CTP is a selective 5-hydroxytryptamine (5-HT) re-uptake inhibitor that blocked the re-uptake of transporters, while MTP could enhance noradrenergic and serotonergic neurotransmission (Salomone et al., 2011). Heartbeat was significantly stimulated by psychoactive drugs (CTP/MTP), which can be used to reflect the toxicological effects on individuals (Liang et al., 2017). Figure 2A and 2B shows that effects of CTP and MTP on heartbeats of $D$. magna after $24 \mathrm{~h}$ of exposure and $24 \mathrm{~h}$ of recovery, respectively. Generally, In the $24 \mathrm{~h}$ of exposure period, the heartbeats of $D$. magna significantly increased in the exposed groups $(p<0.01)$ except Group Mix-H. For MTP, the heartbeats of $D$. magna increased with the increase of pollutant concentration, showing a concentration-dependent mode. On the contrary, the heartbeats of $D$. magna decreased with the increasing concentration of CTP and mixed drugs. Those may be related to the higher sensitivity of $D$. magna to CTP suggesting that $D$. magna may be damaged which was consistent with the findings of Liang et al. (2017), in which heartbeat was significantly stimulated by low-concentration perfluorooctane sulfonate (PFOS) and inhibited by high-concentration PFOS (the change from a low-dose stimulation to a high-dose inhibition). The heartbeats in the mix groups were lower than the single treatment groups. And the trend was from low dose stimulation to high dose inhibition, it was suggested that the mixed toxicity of the compounds revealed a synergistic toxicity occur.

After recovery for $24 \mathrm{~h}$, there were no obvious differences in heartbeat between control group and exposed groups. It was interesting to note that the heart rate decreased slightly with the increasing concentration of MTP, CTP and their mixed drugs after $24 \mathrm{~h}$ of recovery. It was possible that D. magna was damaged after exposure to high concentrations of pollutants, but whether the damage decreased with time needs further studies.

\subsection{Enzyme activity}

Digestive tract has primary sites of toxicant uptake in D. magna. Trypsin and a-amylase were synthesized in the digestive F-cell of crustaceans found in the alimentary tract (Lehnert and Johnson, 2002). The effects of CTP and MTP on the digestive enzymes (AMS and trypsin) of $D$. magna were investigated to identify the potential mechanisms for the feeding inhibition, and the results are shown in Fig. 3. AMS are involved in fibrin and starch digestion in D. magna, while trypsin in protein digestion (Perera et al., 2012; Huang et al., 2017). All of them are the typical digestive enzymes (Houde et al., 2013). Figure 3A and 3B shows that the activities of AMS after $24 \mathrm{~h}$ of exposure and $24 \mathrm{~h}$ of recovery, respectively. Compared with the control, the AMS activities of exposed daphnia increased significantly in Group M-L, M-H and Mix- $\mathrm{H}$ after $24 \mathrm{~h}$ of exposure $(p<0.05)$, the increase activities of AMS could be an adaptation to maximize utilization of the limited amount of food ingested (Seyoum et al., 2021). Those in Group C-L and C-H decreased significantly $(p<0.05)$, which associated with damage to the digestive system of D. magna. The previous study also found that the activity of AMS was decreased significantly after exposed to azithromycin, and the concentration-response relationship was present (Li et al., 2020). There was no significant difference in the AMS activities between Mix-L and control group $(p>0.05)$, which indicated that the different effects on the activity of AMS may be related to different pollutants. After recovery for $24 \mathrm{~h}$, the AMS activities of exposed daphnia increased significantly in Group M-L and M-H, while decreased significantly in Group C-H, Mix- $\mathrm{L}$ and Mix-H $(p<0.05)$. There was no significant change in Group C-L $(p>0.05)$. It indicated that the digestive system of $D$. magna was injured by contaminants, then the AMS activities were not well recovered.

Figure 3C and 3D shows that the activities of trypsin after $24 \mathrm{~h}$ exposure and $24 \mathrm{~h}$ recovery, respectively. After $24-\mathrm{h}$ exposure, the trypsin activities of exposed daphnia increased significantly in Group M-L and Mix-L $(p<0.05)$, which suggested that tissue protein may undergo

Page 5/13 
proteolysis. Protein was reported to serve as an alternate source of energy under extreme stress conditions (Suryavanshi et al., 2009). Stimulating the activity of trypsin may be an adaptive response of $D$. magna to extreme conditions (Dai et al., 2014). There was no significant difference in trypsin activities between Group M-H, CTP and Mix-H and control group $(p>0.05)$. The activities of trypsin were negatively correlated with the concentrations in the MTP and mixed groups, and changed from stimulative effects to inhibition effects with the increase of concentration, which possibly related to the excitatory effect (Liu et al., 2012; Rhee et al., 2013). However, the activities of trypsin were positively correlated with the concentration in the CTP, which might be related to the assimilation processes (Lv et al., 2017). After $24 \mathrm{~h}$ recovery, the activity of trypsin was decreased significantly in Group C-L and increased significantly in Group Mix-H $(p<0.05)$, and there was no significant change in the rest exposed groups $(p>0.05)$

\subsection{Gene transcription of D. magna}

It was found that the pollutants could affect the feeding and nutrition-related enzyme activities of $D$. magna. The nutritional enzyme gene was used as exploratory data to further analyze the possible cause of damage to $D$. magna caused by pollutants. Chronic exposure to hexachlorocyclopendiene (HCCDP), Houde et al. (2013) used transcriptome tools to identify five significant differential in genomic transcription related to metabolic function, including amylase and trypsin. Therefore, gene transcription involved in digestive enzyme synthesis was selected for evaluation based on the changes of amylase and trypsin in order to further explain the possible mode of action of pollutants to $D$. magna. Figure 4A shows that the up-regulated significantly of transcription of AMS genes in all the exposed groups $(p<0.01)$. Moreover, the up-regulated of the Mix groups were smaller than the one of MTP group. This indicated that CTP, MTP and their mixture stimulated the transcription of AMS genes during exposure period and the mixed toxicity of the compounds revealed a synergistic toxicity. It has been reported that SSRI increases the oxygen consumption rate and aerobic catabolism of $D$. magna, and decreases the carbohydrate level of adult Daphnia magna (Campos et al., 2012b). The upregulation of digestive genes may be regarded as a compensation mechanism for reduced carbohydrate reserves (Soetaert et al., 2007). This was consistent with the results of the Houde et al. (2013), in which the transcription of AMS genes was stimulated in the groups added with hexachlorocyclopentadiene (HCCPD). However, this phenomenon was contrary to the results of Zhao et al. (2019), in which the transcription levels of AMS gene were inhibited in the groups with BDE-47, BDE-99 and their mixture. Those indicated that the different effects on the transcription of AMS gene may be related to different pollutants. After $24 \mathrm{~h}$ of recovery, the damage of the target chemicals on $D$. magna was alleviated, but it requires further study to validate whether this damage can be completely removed.

In Fig. 3A, the activities of AMS increased significantly in MTP exposed daphnia after $24 \mathrm{~h}$ of exposure, and the gene transcription of AMS was up-regulated significantly (Fig. 4A). However, there was no significant correlation between gene transcription and enzyme activity of $A M S$ ( ${ }^{2}=$ $0.1753, p=0.266$, Fig. $5 A$ ). The activity of AMS of daphnia was decreased significantly in Group Mix-L and Mix- $\mathrm{H}$ after $24 \mathrm{~h}$ recovery, and the gene transcription level of AMS in those groups was decreased significantly $(P>0.05)$ (Fig. 4B). Correlation analysis was conducted with enzyme activity and gene transcription, and the results showed no significant correlation between both $\left(R^{2}=0.0002, P=0.787, F i g .5 B\right)$. And no significant correlation between gene transcription level and enzyme activity in trypsin. Houde et al. (2013), showed that the activity of AMS was decreased significantly while $D$. magna exposed to HCCPD, and the gene transcription levels of AMS were decreased significantly. Schwarzenberger and Fink (2018) found that there was significant correlation between enzyme activity and gene transcription. These results suggested that enzyme activity and gene transcription may exhibit different responses to various environmental stress. The Study of gene transcription can help understand the possible modes of action of pollutant stressors to aquatic organisms. Gene transcription is the basis of organism's response to external pressure. However, the relationship between gene transcription and related enzyme activity is complex. The lack of correlation between enzyme activity and gene transcription may be related to the time required for gene transcription and many different factors involved in gene transcription process, which increased the uncertainty of the transcription process (Ashouri and Farshbaf Pourabad, 2021).

\section{Conclusions}

In this study, the toxicity of CTP, MTP and their mixtures on the feeding behavior and bodily functions of $D$. magna was investigated. The aquatic toxicity of the two psychotropic drugs from two stages of exposure and recovery was evaluated. After exposure, the feeding behavior of $D$. magna was significant inhibited in the Group $\mathrm{C}-\mathrm{H}$ and $\mathrm{Mix}-\mathrm{H}$, and the heart rate increased significantly in all treatment groups. The changes in enzyme activity and gene transcription levels of AMS and trypsin indicated that CTP/MTP and their mixture had different effects on the physical function of $D$. magna. However, there were different responses between enzyme activities with gene transcription. In the recovery period, obvious overcompensation effect in feeding behavior was found in Group $\mathrm{M}-\mathrm{L}$ and $\mathrm{C}-\mathrm{H}$. There were no obvious differences in heartbeat and the damage of the target chemicals on $D$. magna was alleviated at the genomic level. Those results demonstrated that there were obvious toxicity effects of psychoactive drugs on $D$. magna at the molecular level under single and mixed environmental stress. Further research is needed to determine the toxic pattern of those compound contaminations and investigate the potential mechanisms of their toxicity.

\section{Declarations}

5.1 Ethics approval and consent to participate 
Not applicable

\subsection{Consent for publication}

Not applicable

5.3 Availability of data and materials

Not applicable

5.4 Competing interests

The authors declare that they have no competing interests

5.5 Authors' contributions

Yunfeng Ma \& Dong Xu: carried out experiments, analyzed experimental results and wrote the paper; Chenyang Li and Shu Wei: developed the methodology; Ruixin Guo: analyzed experimental results; Yang Li: developed the methodology; Jianqiu Chen and Yanhua Liu: managed and coordinated responsibility for the research activity planning and execution.

5.6 Funding and acknowledgements

This work was supported by the National Natural Science Foundation of China (21876207), Research Project of Ecological Environment in Jiangsu Province (2020004), Double First-Class University Project (CPU2018GY21, 24), and College Undergraduate Training Program for Innovation and Entrepreneurship.

\section{References}

1. Ashouri S, Farshbaf Pourabad R (2021) Regulation of gene expression encoding the digestive alpha-amylase in the larvae of Colorado potato beetle, Leptinotarsa decemlineata (Say) in response to plant protein extracts. Gene 766:145159

2. Bachour R L, Golovko O, Kellner M (2020) Behavioral effects of citalopram, tramadol, and binary mixture in zebrafish (Danio rerio) larvae. Chemosphere 238: 124587

3. Balakrishna K, Rath A, Praveenkumarreddy Y (2017) A review of the occurrence of pharmaceuticals and personal care products in Indian water bodies. Ecotoxicol Environ Saf 137: 113-120

4. Bergheim M, Giere R, Kummerer K (2012) Biodegradability and ecotoxicitiy of tramadol, ranitidine, and their photoderivatives in the aquatic environment. Environ Sci Pollut Res Int 19:72-85

5. Bownik A (2017) Daphnia swimming behaviour as a biomarker in toxicity assessment: A review. Sci Total Environ 601-602:194-205

6. Bownik A (2020) Physiological endpoints in daphnid acute toxicity tests. Sci Total Environ 700: 134400.

7. Bownik A, Jasieczek M, Kosztowny E (2020) Ketoprofen affects swimming behavior and impairs physiological endpoints of Daphnia magna. Science of the Total Environment 725.

8. Campos B, Pina B, Barata C (2012a) Mechanisms of Action of Selective Serotonin Reuptake Inhibitors in Daphnia magna. Environ Sci Technol 46:2943-2950.

9. Campos B, Pina B, Barata C C (2012b) Mechanisms of action of selective serotonin reuptake inhibitors in Daphnia magna. Environ Sci Technol 46: 2943-2950.

10. Carlson J M, Leonard A B, Hyde E R (2017) Microbiome disruption and recovery in the fish Gambusia affinis following exposure to broadspectrum antibiotic. Infect Drug Resist 10: 143-154.

11. Cipriani A, Furukawa T A, Salanti G (2018) Comparative efficacy and acceptability of 21 antidepressant drugs for the acute treatment of adults with major depressive disorder: a systematic review and network meta-analysis. The Lancet 391:1357-1366.

12. Dai L, Qian X, Nan X (2014) Effect of cardiac glycosides from Nerium indicum on feeding rate, digestive enzymes activity and ultrastructural alterations of hepatopancreas in Pomacea canaliculata. Environ Toxicol Pharmacol 37: 220-227.

13. de Alkimin G D, Nunes B, Soares A M V M (2020) Daphnia magna responses to fish kairomone and chlorpromazine exposures. Chem-Biol Interact 325.

14. Giang PT, Sakalli S, Fedorova G (2018) Biomarker response, health indicators, and intestinal microbiome composition in wild brown trout (Salmo trutta m. fario L.) exposed to a sewage treatment plant effluent-dominated stream. Sci Total Environ 625: 1494-1509.

15. Golovko O, Rehrl AL, Kohler S (2020) Organic micropollutants in water and sediment from Lake Malaren, Sweden. Chemosphere 258, 127293. 
16. Gros M, Ahrens L, Leven L (2020) Pharmaceuticals in source separated sanitation systems: Fecal sludge and blackwater treatment. Sci Total Environ 703: 135530.

17. Gundlach M, Augustin M, Smith KEC (2021) Effects of the antidepressant mirtazapine on the swimming behaviour and gene expression rate of Danio rerio embryos - Is the sedating effect seen in humans also evident for fish? Sci Total Environ 792:148368.

18. He L, Xiao K, Zhou C (2019). Insights into pesticide toxicity against aquatic organism: QSTR models on Daphnia Magna. Ecotoxicol Environ Saf 173:285-292.

19. Hossain MS, Kubec J, Guo W (2021) A combination of six psychoactive pharmaceuticals at environmental concentrations alter the locomotory behavior of clonal marbled crayfish. Sci Total Environ 751:141383.

20. Houde M, Carter B, Douville M (2013). Sublethal effects of the flame retardant intermediate hexachlorocyclopentadiene (HCCPD) on the gene transcription and protein activity of Daphnia magna. Aquat Toxicol 140-141: 213-219.

21. Huang Y, Liu J, Pang T (2017) Growth inhibitory and antifeedant effects of sublethal concentrations of toosendanin on the rotifer Brachionus plicatilis. Biomass and Bioenergy 99:31-37.

22. Kosma Cl, Nannou Cl, Boti VI (2019) Psychiatrics and selected metabolites in hospital and urban wastewaters: Occurrence, removal, mass loading, seasonal influence and risk assessment. Sci Total Environ 659:1473-1483.

23. Kuzmanovic M, Ginebreda A, Petrovic M (2015) Contaminants of Emerging Concern in Mediterranean Watersheds. Emerging Contaminants in River Ecosystems, pp: 27-45.

24. Lari E, Gauthier P, Mohaddes E(2017) Interactive toxicity of Ni, Zn, Cu, and Cd on Daphnia magna at lethal and sub-lethal concentrations. J Hazard Mater 334: 21-28.

25. Lehnert SA, Johnson SE (2002) Expression of hemocyanin and digestive enzyme messenger RNAs in the hepatopancreas of the Black Tiger Shrimp Penaeus monodon. Comp Biochem Phys B 133: 163-171.

26. Li Y, Ma Y, Yang L (2020) Effects of azithromycin on feeding behavior and nutrition accumulation of Daphnia magna under the different exposure pathways. Ecotoxicol Environ Saf 197: 110573.

27. Liang R, He J, Shi Y (2017) Effects of Perfluorooctane sulfonate on immobilization, heartbeat, reproductive and biochemical performance of Daphnia magna. Chemosphere 168:1613-1618

28. Liu W, Ming Y, Huang Z (2012) Impacts of florfenicol on marine diatom Skeletonema costatum through photosynthesis inhibition and oxidative damages. Plant Physiol Biochem 60: 165-170.

29. Liu Y, Guo R, Tang S (2018) Single and mixture toxicities of BDE-47, 6-OH-BDE-47 and 6-MeO-BDE-47 on the feeding activity of Daphnia magna: From behavior assessment to neurotoxicity. Chemosphere 195: 542-550.

30. Liu Y, Yan Z, Zhang L (2019) Food up-take and reproduction performance of Daphnia magna under the exposure of Bisphenols. Ecotoxicol Environ Saf 170: 47-54.

31. Livak KJ, Schmittgen TD (2001) Analysis of relative gene expression data using real-time quantitative PCR and the 2(-Delta Delta C(T)) Method. Methods 25:402-408.

32. Lv X, Huang B, Zhu X (2017) Mechanisms underlying the acute toxicity of fullerene to Daphnia magna: Energy acquisition restriction and oxidative stress. Water Res 123:696-703.

33. Lv X, Yang Y, Tao Y (2018) A mechanism study on toxicity of graphene oxide to Daphnia magna: Direct link between bioaccumulation and oxidative stress. Environ Pollut 234:953-959.

34. Minguez L, Pedelucq J, Farcy E (2016) Toxicities of 48 pharmaceuticals and their freshwater and marine environmental assessment in northwestern France. Environ Sci Pollut Res Int 23: 4992-5001.

35. Perera E, Rodriguez-Viera L, Rodriguez-Casariego J (2012) Dietary protein quality differentially regulates trypsin enzymes at the secretion and transcription level in Panulirus argus by distinct signaling pathways. J Exp Biol 215:853-862.

36. Petrie B, Barden R, Kasprzyk-Hordern B (2015) A review on emerging contaminants in wastewaters and the environment: current knowledge, understudied areas and recommendations for future monitoring. Water Res 72: 3-27.

37. Proctor K, Petrie B, Lopardo L (2021) Micropollutant fluxes in urban environment - A catchment perspective. J Hazard Mater 401 : 123745.

38. Rhee JS, Kim BM, Jeong CB (2013) Effect of pharmaceuticals exposure on acetylcholinesterase (AchE) activity and on the expression of AchE gene in the monogonont rotifer, Brachionus koreanus. Comp Biochem Physiol C Toxicol Pharmacol 158: $216-224$.

39. Salomone A, Di Corcia D, Gerace E (2011) A Fatal Case of Simultaneous Ingestion of Mirtazapine, Escitalopram, and Valproic Acid. J Anal Toxicol 35: 519-523.

40. Schwarzenberger A, Fink P (2018) Gene expression and activity of digestive enzymes of Daphnia pulex in response to food quality differences. Comp Biochem Physiol B Biochem Mol Biol 218:23-29.

41. Sehonova P, Svobodova Z, Dolezelova P (2018) Effects of waterborne antidepressants on non-target animals living in the aquatic environment: A review. Sci Total Environ 631-632:789-794

Page $8 / 13$ 
42. Seyoum A, Kharlyngdoh JB, Paylar B (2021) Sublethal effects of DBE-DBCH diastereomers on physiology, behavior, and gene expression of Daphnia magna. Environ Pollut 284: 117091.

43. Silva LJG, Pereira AMPT, Meisel LM (2015) Reviewing the serotonin reuptake inhibitors (SSRIs) footprint in the aquatic biota: Uptake, bioaccumulation and ecotoxicology. Environ Pollut 197:127-143.

44. Soetaert A, Vandenbrouck T, van der Ven K (2007) Molecular responses during cadmium-induced stress in Daphnia magna: Integration of differential gene expression with higher-level effects. Aquat Toxicol 83: 212-222.

45. Styrishave B, Halling-Sorensen B, Ingerslev F (2011) Environmental risk assessment of three selective serotonin reuptake inhibitors in the aquatic environment: a case study including a cocktail scenario. Environ Toxicol Chem 30: 254-261.

46. Suryavanshi U, Sreepada RA, Ansari ZA (2009) A study on biochemical changes in the penaeid shrimp, Metapenaeus monoceros (Fabricius) following exposure to sublethal doses of organochlorine pesticide (endosulfan). Chemosphere 77:1540-1550.

47. Tkaczyk A, Bownik A, Dudka J (2021) Daphnia magna model in the toxicity assessment of pharmaceuticals: A review. Sci Total Environ 763: 143038.

48. Yan ZY, Yang QL, Jiang WL(2018) Integrated toxic evaluation of sulfamethazine on zebrafish: Including two lifespan stages (embryo-larval and adult) and three exposure periods (exposure, post-exposure and re-exposure). Chemosphere 195:784-792.

49. Yang H, Lu G, Yan Z (2018) Influence of suspended sediment characteristics on the bioaccumulation and biological effects of citalopram in Daphnia magna. Chemosphere 207: 293-302.

50. Yang H, Lu G, Yan Z (2017) Biological effects of citalopram in a suspended sediment-water system on Daphnia magna. Environ Sci Pollut Res Int 24: 21180-21190.

51. Zhao Y, Wang Z, Li D (2019) Two PBDEs exposure inducing feeding depression and disorder of digestive and antioxidative system of Daphnia magna. Ecotoxicol Environ Saf 176:279-287.

52. Zhuang C, Hospital QT (2019) Clinical Effect of Citalopram Combined with Mirtazapine in the Treatment of Sleep Disorders in Patients with Depression. World Journal of Sleep Medicine.

\section{Figures}



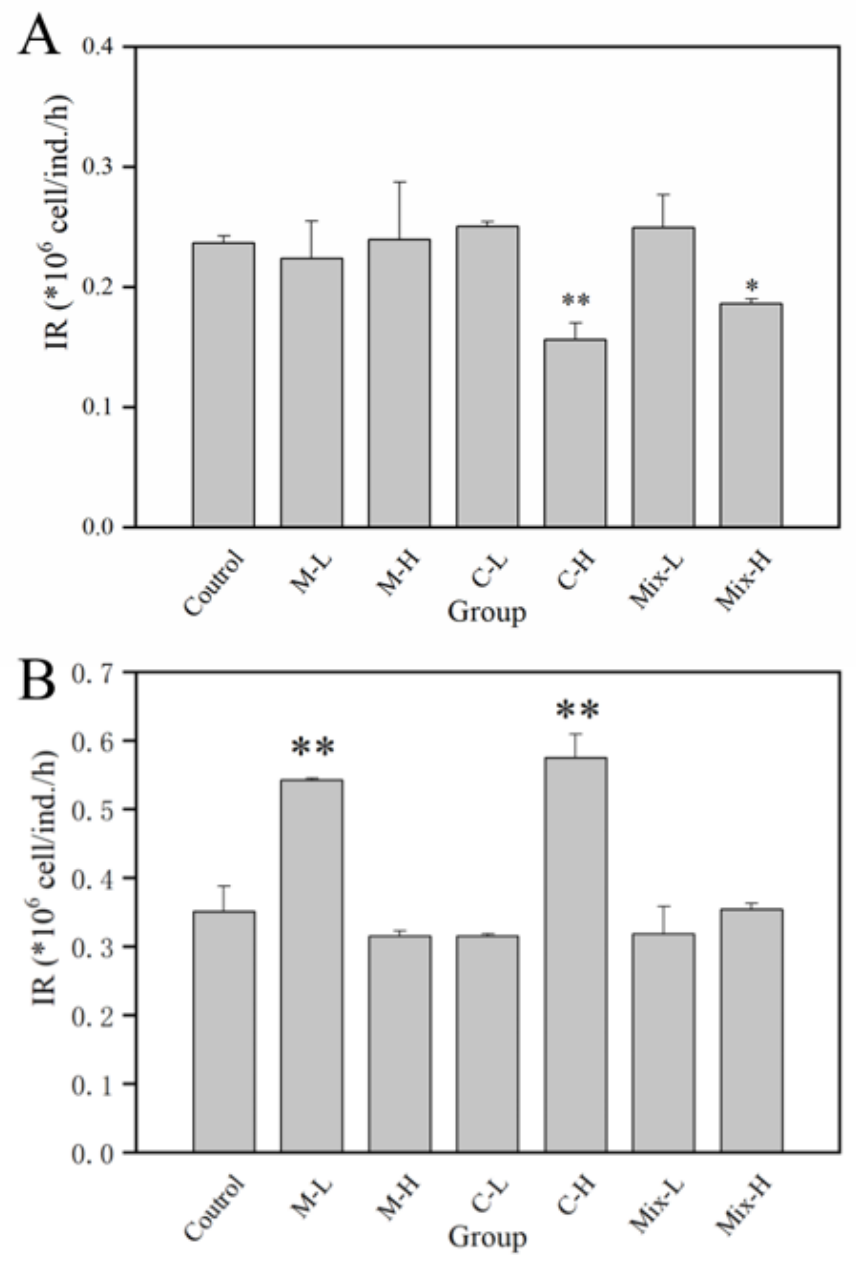

Figure 1

Effects of CTP and MTP on feeding behavior of D. magna after exposure period (A) and recovery period (B). Abbreviations: M-L, mirtazapinelow concentration; $\mathrm{M}-\mathrm{H}$, mirtazapine- high concentration; $\mathrm{C}-\mathrm{L}$, citalopram- low concentration; $\mathrm{C}-\mathrm{H}$, citalopram- high concentration; Mix-L, mixturelow concentration; Mix-H, mixture- high concentration; *: statistical significance of the correction $(p<0.05)$; $* *$ : statistical significance of the correction $(p<0.01)$. 

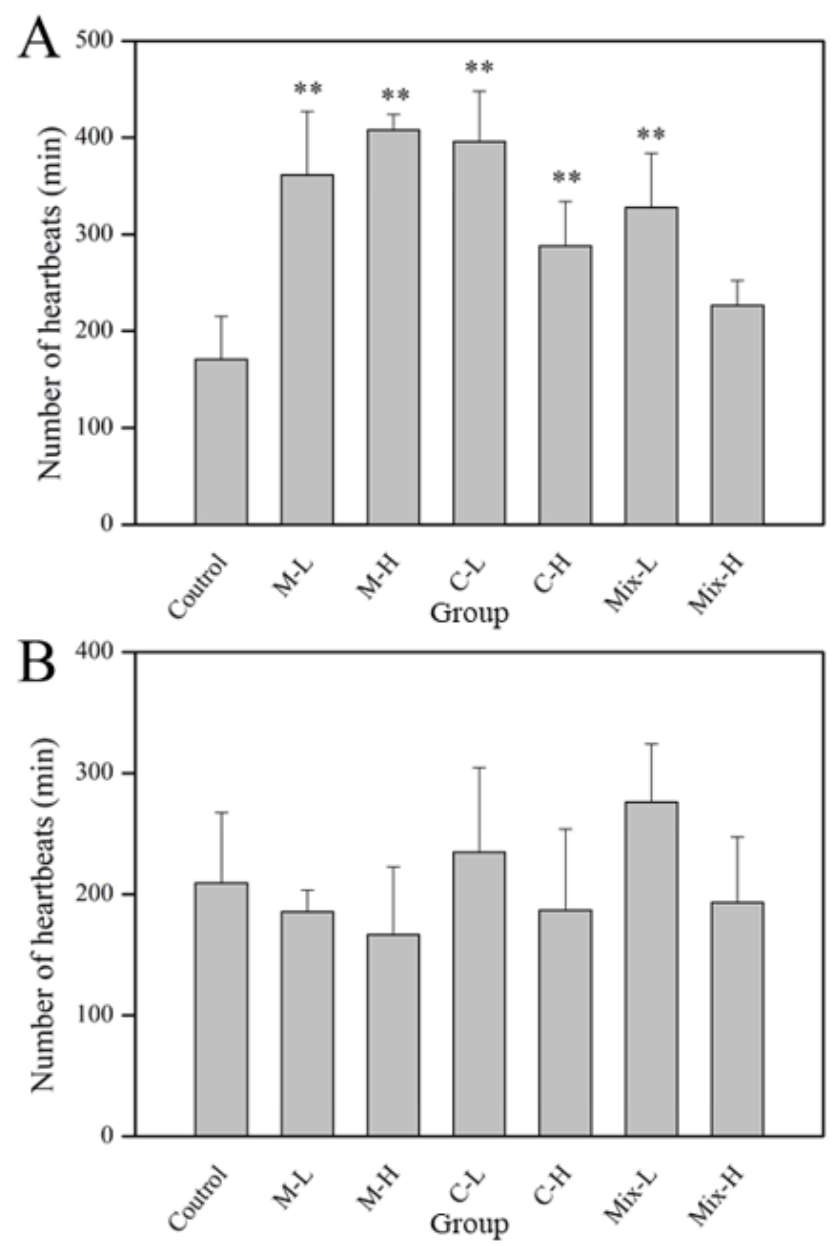

Figure 2

Effects of CTP and MTP on heartbeats of D. magna after exposure period (A) and recovery period (B). Abbreviations: M-L, mirtazapine- low concentration; M-H, mirtazapine- high concentration; C-L, citalopram- low concentration; C-H, citalopram- high concentration; Mix-L, citalopram and mirtazapine- low concentration; Mix- $\mathrm{H}$, citalopram and mirtazapine- high concentration; *: statistical significance of the correction ( $\mathrm{p}$ < 0.05 ); **: statistical significance of the correction $(p<0.01)$.
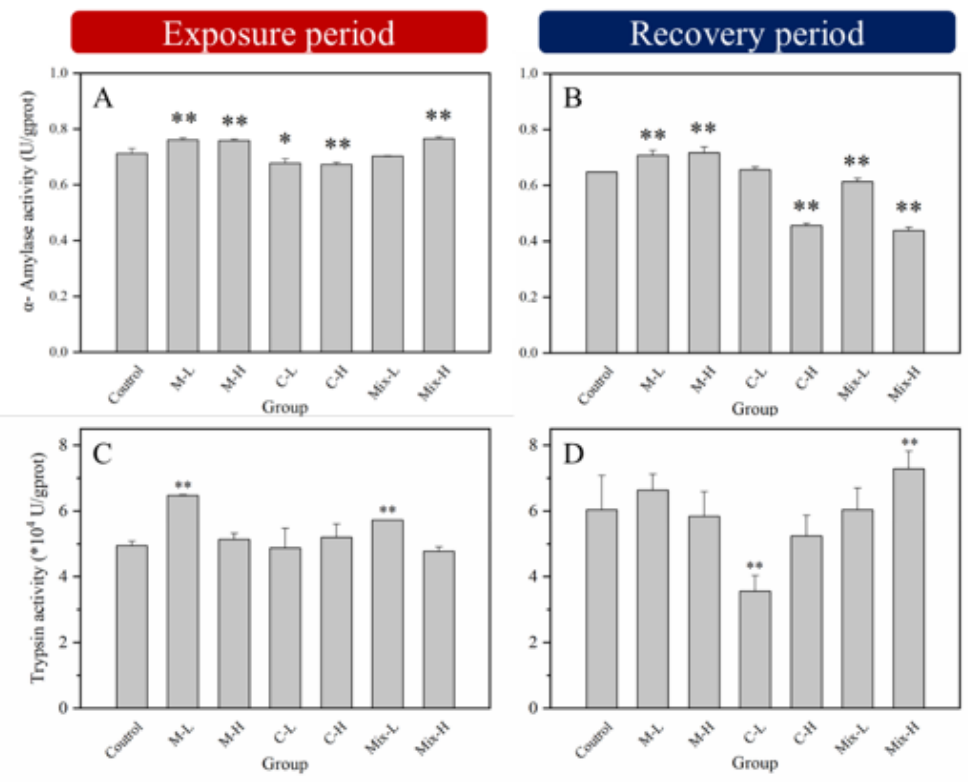

Page $11 / 13$ 


\section{Figure 3}

a-Amylase and trypsin activities of D. magna in different treatment groups after exposure period and recovery period. A: a-amylase activities after exposure period; $B$ : $a$-amylase activities after recovery period; $C$ : trypsin activities after exposure period; and $D$ : trypsin activities after recovery period. Abbreviations: M-L, mirtazapine- low concentration; $M-H$, mirtazapine- high concentration; C-L, citalopram- low concentration; C$\mathrm{H}$, citalopram- high concentration; Mix-L, citalopram and mirtazapine- low concentration; Mix-H, citalopram and mirtazapine- high concentration; *: statistical significance of the correction $(p<0.05)$; $* *$ statistical significance of the correction $(p<0.01)$.
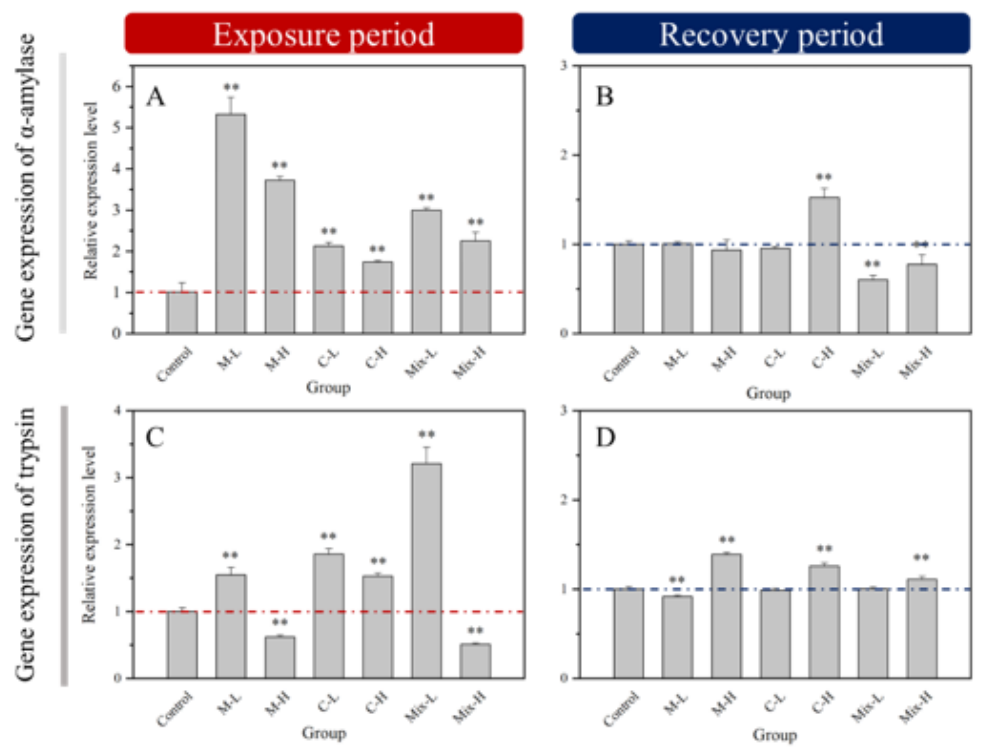

\section{Figure 4}

Relative gene expression of a-amylase and trypsin of D. magna in different treatment groups after exposure period and recovery period. A: $a$ amylase after exposure period; B: a-amylase after recovery period; C: trypsin after exposure period; and D: trypsin after recovery period. Gene transcription below 1 represented down-regulation and above 1 represented up-regulation. All data represented means \pm SD $(n=6$, three biological repeats and two technical repeats). Abbreviations: $M-L$, mirtazapine- low concentration; $M-H$, mirtazapine- high concentration; $C-L$, citalopram- low concentration; C-H, citalopram- high concentration; Mix-L, citalopram and mirtazapine- low concentration; Mix-H, citalopram and mirtazapine- high concentration; *: statistical significance of the correction $(p<0.05)$; $* *$ : statistical significance of the correction $(p<0.01)$. 

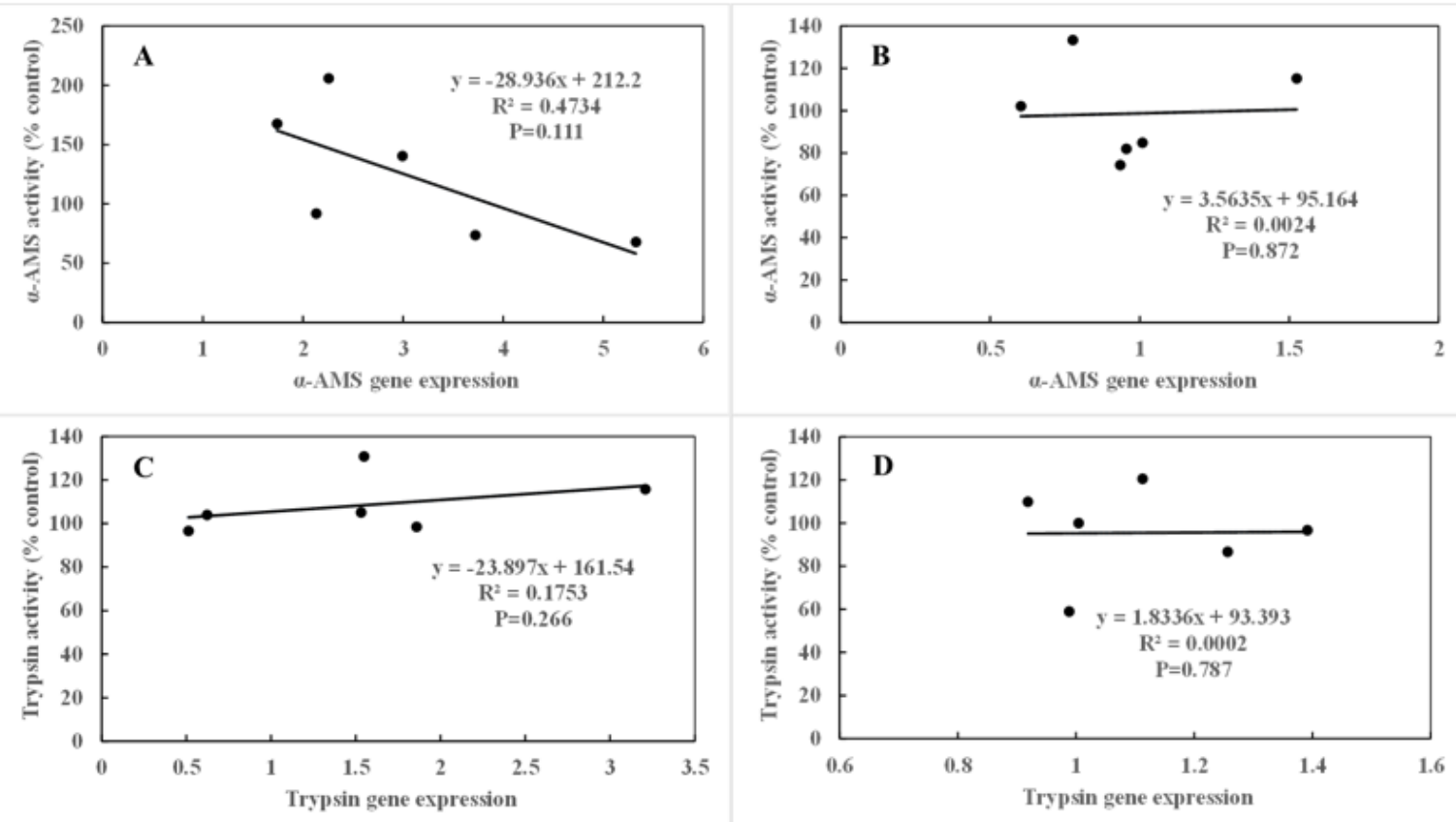

Figure 5

Relationship between gene expression and enzyme activity in exposure daphnia. A: 24 h-AMS; B: 48 h-AMS; C: 24 h-trypsin and D: 48 h-trypsin. Gene expression and enzyme activity are listed in X-axis and Y-axis, respectively. Regression lines and R2 values are delineated.

\section{Supplementary Files}

This is a list of supplementary files associated with this preprint. Click to download.

- Supplementarymaterial.docx

- GraphicalAbstract.png 